\title{
Mesa Redonda «EI Porvenir de las Humanidades en la Sociedad del Conocimiento» ${ }^{1}$
}

\author{
Wáshington Delgado Tresierra
}

[Alude a la intervención previa de Hugo Neyra] muy brillante, Neyra es un expositor, digamos, avezado, tal vez por su ejercicio periodístico. Sabe exponer muy bien. Nos ha dicho muchas cosas importantes, muchas cosas discutibles, que espero que ustedes las discutan. No me atrevería a tanto, porque ha hablado de muchos temas en general. Tiene una formación humanística muy amplia, no en una sola disciplina, sino en varias disciplinas que en esta Facultad se llaman Ciencias Humanas.

Voy a empezar con una cosa menor, en cierto modo más ceñida. Yo he sido profesor de literatura durante muchos años y voy a empezar a hablar, pues, de la poesía. Ahora se discute, bueno, no se discute, sino se siente, un cierto desinterés o desmedro en el conjunto de la sociedad por las humanidades. Pero lo que está de moda no es tanto la ciencia tampoco. Hay que recordar, lo ha dicho ya Hugo Neyra, la ciencia experimental y el humanismo aparecen juntos. Los griegos tenían unos estudios humanísticos y los latinos también. Pero no había ciencia experimental. Esa es una creación moderna. Pero me voy a reducir a la poesía. Hay un cierto desinterés del conjunto de la sociedad por las humanidades. Nosotros vemos, aquí en el Perú, por ejemplo ¿cuántas universidades hay? Hay cincuenta, sesenta, setenta universidades, contando las universidades públicas, o llamadas públicas, y las universidades privadas. Sobre todo en los últimos años se han multiplicado las universidades privadas. Uno camina por una calle y se encuentra con una universidad. Por cualquier sitio, por cualquier

\footnotetext{
El texto es la transcripción de su intervención en una mesa redonda efectuada el 20 de agosto de 2003, que formaba parte de las actividades por el 450 aniversario de la Facultad. Lamentablemente, por fallas imperdonables del personal encargado de la filmación, el texto presenta algunas lagunas, sobre todo en el remate final de la intervención. Sin embargo, por el interés de las ideas planteadas y a modo de homenaje al maestro, hemos optado por publicar el texto aun con esas deficiencias.
} 
lugar de Lima hay universidades. Y de esas universidades setenta, ochenta, ¿cuántas universidades tienen estudios de humanidades? Muy pocas. Aquí en Lima, bueno, San Marcos. Estamos hablando de cuatrocientos cincuenta años de la fundación de San Marcos, que empezó con cuatro facultades: Teología, Derecho, Medicina y Artes, que eran Humanidades. Se estudiaba en cierto modo mucho de lo que se estudia ahora. En el noventa por ciento de las universidades no hay facultad de humanidades, no existe. Se entra pues en una cierta decadencia social de los estudios de humanidades. En este momento predominan los factores económicos. Lo cierto es que el que estudia humanidades estudia porque le gusta; pero no porque se va a volver rico haciendo filosofía. Ahora se prefiere, ni siquiera las carreras científicas, sino las carreras en cierto modo técnicas, operativas. Es la técnica lo que domina en este momento. Y hacia eso van casi todos los estudiantes. Las humanidades, como ha dicho Hugo Neyra, puede pensarse que son como un adorno, que no tienen mayor uso. Volveremos sobre eso.

Veamos ahora en primer lugar en la poesía. Jean Cocteau dijo alguna vez: la poesía es evidentemente útil, lo que quisiera saber es para qué. Y es así. No hay una utilidad inmediata en la poesía. Pero ustedes no encuentran una cultura que no tenga poesía. Desde las más primitivas, desde las más remotas, existe poesía. $\mathrm{O}$ sea, hay una necesidad de la poesía. ¿Para qué? No sabemos, pero no se puede vivir sin poesía. En los terrenos más alejados de las humanidades, en los barrios marginados, en las discotecas hay poesía. En las canciones, en los blues, en los boleros o en el rock, hay poesía, no será la elevada poesía de Virgilio, de Goethe, pero donde hay núcleo, ahí la poesía subsiste. Ahora bien, los temas de la poesía, de la literatura, no son muchos. En uno de los ladrillos babilónicos de hace cuatro mil años, un poeta escribe: ya no hay nada sobre lo cual se pueda escribir, todo ha sido dicho. Hace cuatro mil años. Y si se observa la poesía o la literatura en general, los temas se repiten. Andre Gide dice: todo ha sido dicho en el arte ya, pero hay que volver a decirlo, porque la gente no escucha. Tenemos que decirlo de nuevo, y cada vez decir lo mismo de otra manera, y es esta la riqueza de la literatura.

El acabamiento de la literatura ha sido visto muchas veces, por ejemplo, en el caso de la novela. Hacia 1905 Ortega y Gasset escribe un libro que se llama $L a$ deshumanización del arte, en el cual dice que la novela es un género muy 
moderno. La novela propiamente tal como la entendemos ahora, surge en el siglo XIX, probablemente con Rojo y Negro de Stendhal que es la primera novela, hay protonovelas anteriores, pero novela, novela como la entendemos ahora, empieza con Stendhal y sigue con Balzac, Flaubert y todos los escritores realistas. Había visto muchos temas, los había desarrollado, pero los empezaba a repetir. Y entonces Ortega dice una cosa: la novela se está acabando, porque ya no hay nada que decir con la novela. Cinco o seis u ocho años después, aparece un nuevo tipo de novela, la de Proust, que todavía es perfeccionada por Joyce, que es otra cosa completamente distinta a la novela anterior, pero es novela. $Y$ la novela ha ido cambiando, hasta el momento actual, en que aparecen nuevas maneras de hacer novela, y la novela no desaparece, y por lo que parece no va a desaparecer.

Cuando yo estudiaba en San Marcos, había una polémica, no sé si la recuerda Neyra, se discutía mucho. Y había muchos libros norteamericanos, europeos, sobre el acabamiento de la poesía. Una de las teorías sobre qué cosa es la poesía, qué cosa es la literatura en general, es que es una vida ficticia. Se hace literatura porque no podemos hacer lo que queremos, tenemos apetencias que no podemos desarrollar. De ahí surge la literatura. La literatura muestra aquello que no podemos hacer, ni vivir. Es una vía de escape. La literatura nos satisface en un mundo que no nos satisface. Usted debe pensar, bueno este mundo va cambiando. Hace cincuenta años o sesenta años se pensaba que la revolución estaba ahí. Ya había habido el gran experimento ruso, todavía no había habido lo de Cuba, estaba por hacer. Se pensaba: cuando cambie la sociedad, cuando lleguemos a un estado socialista en que todos van a gozar de todos los bienes, ya la vida en sí misma va a ser una satisfacción. Entonces ya no necesitaremos escritores que se dediquen a una vida ficticia, porque todos harán lo que quieran. Entonces la poesía va a desaparecer. Y sobre eso se discutía, se discutían las posibilidades de subsistencia de la literatura en un estado, digamos, ideal y perfecto, que se imaginaba cercano. Bueno, en primer lugar el estado perfecto no ha llegado y naturalmente la literatura no ha desaparecido.

Entonces han habido muchas ideas alrededor de esta desaparición, y algo de esto podría decirse del conjunto de las humanidades. Como ha recordado Hugo Neyra, este estudio de las humanidades aparece con el Renacimiento. Ya en el siglo XIV empieza la preocupación renacentista en este sentido. La socie- 
dad medieval, había sido una sociedad teocéntrica. Lo importante era el conocimiento de Dios, llegar a Dios. Lo demás no tenía mayor importancia. Su importancia era pequeña y mediana. Se había olvidado todo lo que habían hecho los griegos y los latinos, se había perdido. Había recuerdos vagos, Virgilio por ejemplo era un brujo, había recuerdos más o menos vagos de algunas cosas, pero por los árabes en primer lugar, por la penetración musulmana que termina por capturar Bizancio, la última gran capital del mundo antiguo. El Imperio Romano se dividió en dos partes: el Imperio Romano de Occidente con Roma a la cabeza, y el de Oriente con Bizancio. Pero este fue capturado por los turcos, y los sabios bizantinos huyeron ante la amenaza turca y se fueron a Italia llevando sus manuscritos griegos, latinos.

Los árabes redescubrieron a Aristóteles, por ejemplo, redescubrieron a los filósofos. Entonces los hombres de estudio, los escritores, los editores, porque en ese momento también coincidentemente aparece la imprenta, se dedicaron al estudio de esos textos que ya no trataban de Dios, sino de muchas cosas, trataban del mundo, de los animales y fundamentalmente del hombre. Era un conocimiento no teológico, hablaban de la arquitectura, pongo por caso, de la historia, del pasado de los pueblos, de la vida humana, y a eso se le llamó las letras humanas, frente a las letras divinas, que eran las de los padres de la Iglesia, San Agustín, San Anselmo, en un tiempo eso era lo verdaderamente importante. Aparece un estudio de otras letras que no son las letras divinas, sino son las letras humanas, porque fueron hechas por gente que no conoció el cristianismo ni el catolicismo, que fue anterior o contemporánea a Cristo, o incluso algunos siglos posterior, pero que no tuvo conocimiento de estas doctrinas, que se dedicó a otras cosas. Algo que sorprende a estos lectores, es que esos hombres de la antigüedad, que habían sido olvidados, en primer lugar eran hombres sabios, con grandes conocimientos que se habían perdido, pero en segundo lugar, la mayor parte eran hombres buenos, y tenían una moral acrisolada, mejor incluso que la moral católica oficial. Todavía no había esta división que se produce también coincidentemente por esta época: la división de la Iglesia Católica. Eran hombres admirables, ya fuera Horacio, Virgilio, o Plinio, eran hombres de una amplitud moral, una riqueza moral realmente maravillosa. Se quedaron sorprendidos, pues. Cómo estos hombres que no conocían a Dios, ni a Jehová, ni nada, sin embargo tenían una vida moralmente admirable, a parte de una sabiduría. En ese momento las humanidades van a coincidir con el naci- 
miento de la ciencia experimental. Por un lado aparecen casualmente los estudios de los escritores no dedicados a la divinidad, sino a problemas humanos, y de otro lado aparece, con Galileo, Copérnico, la ciencia experimental, que no conocieron los griegos, que va a ser el fundamento del desarrollo que vemos ahora, que va a llegar a las computadoras o a la bomba atómica, que va a ser motivo de bienestar o de muerte, aparece pues la ciencia experimental.

En estos siglos se desarrolla el arte, que es casi otra disciplina humanística. Frente a la creencia de que la pintura es un arte manual, Leonardo Da Vinci dice que no, la pintura es un arte mental, no manual. Eso habría que explicarlo, pero efectivamente la pintura de esa época es una pintura sujeta a reglas y a razón, no se pinta así no más, no se copia así no más, se siguen dictados racionales, e incluso matemáticos. La perspectiva por ejemplo, que se encuentra en esa época, sigue leyes geométricas. En esa época, se hace lo que no se había hecho antes, porque había tabúes religiosos también en la antigüedad: se examina el cuerpo humano por dentro. Nunca se había examinado el cuerpo humano por dentro, nunca se había hecho la disección del cuerpo humano. Galeno, un gran médico griego, es notable en la sintomatología de las enfermedades, sus descripciones siguen siendo clásicas, pero nunca había visto un hígado humano, había visto el hígado de una vaca o de un perro. Y, claro, los había relacionado y veía que eran semejantes al hígado humano, pero no había visto como funcionaba. Son los médicos del renacimiento los que lo hacen, y los pintores. Leonardo Da Vinci dibujó muchos atlas anatómicos, de los músculos, de los nervios, del cerebro, del corazón, de los riñones, perfectamente dibujados. Él examinó, abrió los cadáveres. Los escritores también, Rabelais era médico y describe como hace una autopsia. Es el nacimiento de la ciencia que va paralelo al desarrollo de las humanidades. Sin embargo, si bien las humanidades sirvieron para ese desarrollo, pareciera ahora que hay cierto divorcio. La ciencia parece que tiene algo que defender, porque es inmediatamente útil. Pero las humanidades, como la poesía, son útiles. Su utilidad la ha explicado magníficamente Hugo Neyra, y aparte de eso, hay la utilidad que le da Jean Cocteau a la poesía. Es evidentemente útil, ahora no es útil en lo inmediato. Para qué, no lo sabemos, pero es útil. No podemos vivir sin poesía, no podemos vivir sin pensamiento filosófico, es necesario, es una inquietud que hay. 
El estudio de las Humanidades que ustedes están realizando, no se debe a razones pragmáticas, sino a una vocación, y esa vocación es necesaria, es necesario que haya gente que se dedique a eso, sin las miras de ganar dinero. Un gran jurista que tuvo la Universidad de San Marcos, que fue rector de San Marcos, y que era humanista, además un gran humanista, José León Barandiarán, hombre de una sabiduría realmente extraordinaria. Como un ejemplo sobre León Barandiarán, yo creía que el libro de Vallejo, Trilce, no lo habían entendido más o menos sino dos personas en su tiempo. Una era Antenor Orrego, que era su amigo, que formaba parte del mismo grupo, que conocía su pensamiento, que lo había impulsado a escribir, y que escribe el prólogo de Trilce; bueno, él lo había entendido, no totalmente, pero lo había entendido. Y el otro me parece que era Basadre, en algunas notitas de la Historia de la República, Basadre se dio cuenta de muchas cosas. Yo no conocía la polémica de Trilce, hasta que la publicó Puccinelli en una edición del Banco de Crédito, creo, una edición de las Crónicas, hay como tres o cuatro ediciones, la penúltima. Ahí se reproduce la polémica de Trilce, que se realizó en los periódicos del norte, sobre todo en Chiclayo, y que la inició León Barandiarán con un artículo. León Barandiarán era un abogado joven, no había estudiado literatura, pero había leído mucho, explica brillantemente en qué consiste la novedad y el valor de Trilce. Bueno, a este León Barandiarán que era un sabio y que era un gran jurista, magnífico profesor de derecho, Acto Jurídico creo que era su curso, le preguntaron una vez en un reportaje de periódico, yo lo leí: ¿desde cuándo sintió usted la vocación por el derecho? León Barandiarán dijo: no, no hay vocación por el derecho, la vocación es algo muy profundo, puede haber vocación por la música, puede haber vocación por la pintura, por la filosofía, por la política, pero no por el derecho. El derecho es algo útil, no es una cosa de vocación. Y eso es lo que la mayor parte de los estudiantes quieren: algo inmediatamente útil, y tienen perfecta razón, vivimos en un mundo difícil, hay que conseguir la utilidad. Ustedes han preferido las humanidades y me parece muy bien.

Necesitamos siempre un pretexto que es el impulso [laguna en la transcripción]... la perspectiva de los pintores renacentistas, pero también de la filosofía, que va permitir ese avance. Aparecen dos movimientos filosóficos que van a romper con el esquema del pensamiento medieval, de la búsqueda de Dios, la metafísica, la metafísica pasa a segundo plano. De un lado, Descartes. Descartes echa por la borda toda la filosofía anterior, lo importante no es la metafísica 
[nueva laguna, se hace referencia al segundo movimiento, el empirismo] el conocimiento científico. Nosotros vemos una cosa y pensamos, pero la cuestión es examinar lo que vemos, lo que oímos, y eso trae el predominio de la ciencia experimental.

Quisiera agregar algunas cosas sobre la cantidad de información que tenemos, que yo no manejo al detalle, y que creo que es muy útil, pero que también tiene lo que ha dicho Hugo Neyra, si no sabemos manejar esa información, porque hemos aprendido a leer, hemos aprendido a subrayar, hemos aprendido a hacer fichas, hemos aprendido a hacer resúmenes, nos vamos a ver envueltos por esa cantidad de información. Luis Buñuel, el gran director español, en su libro de memorias habla de tres o cuatro males que amenazan a la humanidad, y el primero es la cantidad de información. Tenemos demasiada información, a cada rato estamos con la información, la televisión, la radio, nos llenan de información y perdemos de vista la realidad, por la excesiva cantidad de información. La técnica, puede ser peligrosa. Uno de los avances es la cantidad de información que nos da la computadora, pero nos da algo más que la cantidad de información, la capacidad de resolver problemas en la computadora. La computadora tiene una enorme capacidad, había problemas matemáticos que no se podían resolver algebraicamente pero la computadora traza las gráficas... [Nueva laguna, el final de la exposición no está registrado]. 